\title{
Research on the Influence of Path Dependence on Sharing Economy*
}

\author{
Dandan Li \\ School of Management \\ Beijing Union University \\ Beijing, China \\ Liwei $\mathrm{Li}^{* *}$ \\ School of Management \\ Beijing Union University \\ Beijing, China \\ **Corresponding Author
}

\author{
Yilei Pei \\ School of Management \\ Beijing Union University \\ Beijing, China \\ Xiaojuan Sheng \\ School of Management \\ Beijing Union University \\ Beijing, China
}

\begin{abstract}
Currently, sharing economy is one of the fastest growing economic forms in China. Technological capacity and technology catching-up become very important issues for its development. A technology catching-up model of technological capacity and path dependence is proposed based on Verspagen mode in this article. It is not only to improve its own technological capacity, but also to break through "the locking" of path dependence. For less developed nation (country), the "conscious behavior" of economic body cannot be ignored to achieve the evolution from path dependence to path creation. Thus, the less developed nations (countries) should cultivate their technology ability as well as their creative realization and ability.
\end{abstract}

Keyword-sharing economy; technological capacity; technology catching-up

\section{INTRODUCTION}

Sharing economy is a class of economic arrangements in which asset owners and users mutualize access to the products or services associated with these assets[1] [2].Today, the best-known sharing economy companies do business in a lot of fields, such as bicycle sharing including Mobike, ofo, Unibike; car sharing including Didi, Uber; clothes sharing including rent the runway, Poshmark; knowledge or information sharing including Khan Academy, Zhihu; room sharing including Onefinestay, Airbnb, Couchsurfing; task sharing including Task Rabbit; money sharing including Tilt, Kickstarter; meal sharing including EatWith; office sharing, equipment sharing and so on. In China, the sharing economy market size has reached $\$ 4920.5$

*This work is supported by the Beijing Municipal Education Commission Social Science Program General Project of China (SM201811417008); Premium Funding Project for Academic Human Resources Development in Beijing Union University(BPHR2017DS14); Education Teaching Research and Reform Project of Beijing Union University(JJ2018Q018); Social Science Foundation of Beijing(17GLC050); National Social Science Foundation of China(17BGL265). billion in 2017.

What is sharing economy we using? It is a socioeconomic ecosystem that commonly uses information technologies to connect different stakeholders in order to make value by sharing their excess capacities, products and services [3] [4]. So we define it from a broader view: any sales transactions that enhance the utilization of idle resources largely based on online market places.

The literature on catching-up shows that, relatively backward regions (countries) should grow faster and rely on a technology spillover to narrow the gap with developed regions (countries) because of Technology Spillover Effect. Finally, economic convergence is achieved such as the "leapfrogging" met by the new growth theory. But the fact is that this phenomenon has not been realized in developing regions [5] and there has also been "the advantage of backwardness paradox", that is the technological gap between latedeveloping regions (countries) and developed regions (countries) is increasing. This is related to the "suitability of technology introduction" [6], the matching problem of factor endowments [7] [8], the factors of financial markets efficiency and the various technical barriers [9] that hinder the absorption of technology. Based on the research and conclusion of new growth theory, some scholars believe that the reason why developing regions (countries) haven't realized economic convergence is the cost of technological imitation under the condition that technological progress is still the engine of economic growth. According to Barro, the cost of technological imitation is lower than that of technological innovation [10]. Therefore the developing regions (countries) have advantages such as low cost, rapid economic growth and rising technological level in the early stage of imitation. When the gap between developing regions (countries) and developed regions (countries) is reduced to a certain extent, the difficulty and cost of imitation grow higher, and some core technologies in developed region (country) are difficult to imitate. 
There are also scholars who believe that the technological capabilities (including learning capability and absorptive capability) of late-developing regions (countries) are keys to narrowing the technological gap and achieving technological catch-up [12-15]. That is to say, when a region (country) has stronger technological capabilities, its ability to digest and absorb technology spillovers is stronger. Therefore, the narrowing of technology gap between different regions (countries) can be achieved through technology diffusion and later technological innovation, which speed up the convergence rate of regional (national) economy.

However, the technical catch-up model proposed by these scholars does not consider or explicitly consider the possibility of "lagging behind", and it doesn't include an analysis or the possible causes of backwardness. It only studies how to catch up and surpass [12-13], ignoring the matching problem of resources and the factors of independent innovation in the analysis, so the analysis of the backward equilibrium point is not considered comprehensively.

As for the empirical analysis, Kokko [16] shows that in Mexico when the technology gap exceeds a certain value, it is difficult to catch up. Lee and Lim [17] proposed a threestage technology catch-up mode: path-following, pathskipping and path-creating through an empirical study of industrial technological catch-up in South Korea. Lucia [18], who has conducted a comparative study of Chile, Italy and South Africa in the wine industry, has found that latedeveloping regions (countries) are actively involved in the process of technological modernization and product standardization, influenced by different institutional models and innovation strategies. $\mathrm{Fu}$ [19] holds that developing regions (countries) should not blindly rely on independent innovation, but formulate reasonable strategies according to their resources, labor force and technological capabilities. These scholars generally believe that there is a intimate connection between technological catch-up and technological gap, and the key to narrowing the gap is the $\mathrm{R}$ \& D level of technology, the technical basis, and the educational system of a region (country).

This text thinks that the key to catch up with the technology in the late-developing regions (countries) is how to break through the technology dependence on the technology of leading regions (countries) and then achieve the technological innovation. As he characteristics of selfaccumulation and path dependence, the existed technologies and knowledge are extremely important to the new technologies and knowledge: the more the existed technologies and knowledge, the more obvious the development advantage of the regions (countries) in this respect. From the point of view of technological capability and path dependence, this text will study the model of technological catch-up and overtaking in late-developing regions (countries), which will provide reference and basis for technological catch-up in developing countries.

\section{MODEL OF LATE-DEVELOPING REGIONS (COUNTRIES)}

\section{A. Theoretical Basis: Path Dependence}

This text holds that the dependence of technology itself is also very strong, compared with the concept of path dependence, it can also be called technological dependence. The concept of Path Dependence was originally introduced by Gutman in 1975. Studying the current QWERTY keyboard he found that the keyboard itself was suboptimal, but "unexpected historical events" gave it an initial advantage. Finally, through a series of developments and changes, the leading position of the typewriter keyboard is established, and the keyboard design of all typewriters is "locked" to the sub-optimal QWERTY mode. Today, it is still the design mode of our typewriter keyboard, whose status is unshakable. David defines it is a stochastic dynamic processes of "nonergodicity". That is, the system will continue to evolve under the influence of "unexpected historical events", unable to escape the influence of "unexpected historical events" without the impact of external factors on the system.

It holds that the early accidental historical events will have an important impact on the development of the system, and the development of the socio-economic system is very sensitive to initial conditions. In other words, path dependence is a process which is made up of a series of events and can be enhanced all by itself. The initial state or all the disturbances in the history of the system always affects the development of the system. The adoption of new technologies tends to have the nature of incremental returns [21], that is, if a suboptimal technology is given the opportunity to enter the market first due to accidental initial conditions, it can use its preemptive advantage to expand its scale. The unit cost can be reduced, self-enhanced and being developed sustainable by taking advantage of the consumer habits, the producer learning effect, the cooperation effect of other industries or technologies, and so on. Inversely, though the technology is advanced, it will fall into another vicious circle, and even to be "locked" because of the late entry into the market which loses some of the advantages of firstmover. Therefore, path dependence is similar to the "inertia" phenomenon in physics. Once entering a certain path, it will continue to develop along this path. Dependent on this path no matter whatever reasons and however the advance of the technology,

\section{B. The Features of Path Dependence}

Technological changes of the late-developing regions (countries) have strong path dependence features. Once "dominant technologies" of late-developing regions (countries) relies on the profits, human resource, equipment, managements of the current existed technology, it will form path dependence. In addition, the existed path dependence theories only focus on the breaking of "lock-in" by relying on external factors but ignoring the organizers' subjective initiative.

This text studies the problem of technological catch-up in late-developing regions (countries) based on the technology catch-up model of Verspagen [15], from the point of view of 
technological capability and path dependence. It provides a reference and basis for technological catch-up in latedeveloping regions (countries).

\section{Description of the Model}

Firstly, the technology gap between two regions (countries) is defined as the following formula (1):

$$
G=\ln (K n / K s)
$$

Here $\mathrm{G}$ represents the technology gap; $\mathrm{K}$ represents the existed technological level or knowledge stock; the lower corner marks $\mathrm{n}$ and $\mathrm{s}$ respectively represents the technologyleading regions (countries) and the technology-late regions (countries). When the technical parameters between two regions (countries) are the same, the logarithmic function can conveniently explain the gap between them equals 0 , that is $\mathrm{G}=0$.

Secondly, according to the assumptions above, the relationship between the level of economic development and the level of technology of a region (country) is defined as the following formula (2):

$$
\frac{\dot{E}_{i}}{E_{i}}=\alpha \frac{\dot{K_{i}}}{K_{i}}
$$

Here $E_{i}$ represents the economic level of a region (country), a represents the proportional coefficient between technological growth and economic growth, and $a \in(0,1)$.

Thirdly, define the technological level of the latedeveloping regions (countries) from four aspects: relying on the existed path development, the late-developing regions (countries) are content with the profits and benefits created by current technology even the technology path is not the most advanced. Formula (3) (4) shows the technical stock of two regions (countries).

$$
\begin{aligned}
& \frac{\dot{K}_{s}}{K_{s}}=b \frac{\dot{E}_{s}}{E_{s}}+R_{S}+P_{S} \\
& \frac{\dot{K}_{n}}{K_{n}}=b \frac{\dot{E}_{n}}{E_{n}}+R_{n}
\end{aligned}
$$

Here $S$ represents the technology spillover of the technology leading regions (countries); $R_{s}$ and $R_{n}$ represent the growth rate of the technology brought by the R \& D; $P_{s}$ represents the impact rate of the technology path dependence on the technology growth in the regions (countries). Here technology leading regions (countries) and technology latedeveloping regions (countries) both have the influence of technology dependence, but technology leading regions (countries) have stronger technological innovation. Therefore, from the comparative study of the two, the net effect appears only in formula (3), and the coefficient $\mathrm{b} \in(0 \sim 1)$, which represents the proficiency in technical mastery, as well as the effect and intensity of the influence.
Assumes $\mathrm{n}$ represents a technologically leading region (country), as $S$ doesn't appear in formula (4), so this reflects as follows:

$$
\left.b \frac{\dot{E}_{n}}{E_{n}}+R_{n}\right\rangle c \frac{\dot{E_{s}}}{E_{s}}+R_{s}+P_{s}
$$

Finally, definition of technology spillover effect: the learning ability of a region (country) depends not only on its inherent ability, but also on its technological gap with the leading region (country). The reasons why there exists the technology gap are as follows: technology is a highly heterogeneous product that it is included in highly heterogeneous capital goods. Imagine a product scope includes technologies, and then technologies as a range can be sorted according to the technology level (or productivity). Then, given an entrepreneur (or more generally, a country) using capital goods from the lower part of the range, it is easier to transfer a slightly complicated capital product than to transfer a highly complicated one. Moreover, for a given technological gap, the learning capacity of a region (country) varies from their inherent capacity, which is determined by many social factors ${ }^{[22]}$, the education of the labor force [23], the infrastructure level, the capitalization level (or the mechanization level), the communication capabilities ${ }^{[24]}$ between leading regions (countries) and under developing regions (countries) and other factors. Considering above discussions, the expression of technology spillover effect is shown in formula (5).

$$
S=c G e^{-G / \delta}
$$

In formula (5), the potential spillover rate $(c G)$ is proportional to the technology gap $G$. The learning ability (e$\mathrm{G} / \delta$, where $\delta>0$ ) is a function of internal learning ability $\delta$, and the technology spillover is measured by the technology gap itself, which is consistent with above discussions. For the similar technology gap (i.e. $\mathrm{G}=0$ ), the actual spillover is zero, and the spillover increases when $\delta$ increases.

\section{ANALYSIS ON THE MODEL}

By breaking through path dependence can latedeveloping regions (countries) achieve technological catchup by improving their learning ability? This should only be solved by dynamic analysis of the model. First, put formula (2) into formula (3) and formula (4), we get formula (6) and formula (7) as follows:

$$
\begin{aligned}
& \frac{\dot{K}_{s}}{K_{s}}=\frac{1}{1-a b}\left(S+R_{s}+P_{s}\right) \\
& \frac{\dot{K}_{n}}{K_{n}}=\frac{1}{1-a b} R_{n}
\end{aligned}
$$


By introducing the derivative of time of the technology gap we get formula (8):

$$
\begin{aligned}
& \dot{G}=\frac{d}{d t}\left(\ln \frac{K_{n}}{K_{s}}\right) \\
& =\frac{\dot{K}_{n}}{K_{n}}-\frac{\dot{K}_{s}}{K_{s}} \\
& =\frac{1}{1-a b} R_{n}-\frac{1}{1-a b}\left(S+R_{s}+P_{s}\right) \\
& =\frac{1}{1-a b}\left[\left(R_{n}-R_{s}\right)-\left(S+P_{s}\right)\right]
\end{aligned}
$$

If $R_{n}-R_{s}=\alpha$, which reflects the difference between exogenous technology stock. Put formula (5) into formula (8), we obtain the following dynamic expression formula (9) of the technical gap.

$$
\dot{G}=\left(\alpha-c G e^{-G / \delta}-P_{s}\right) /(1-a b)
$$

Generally, $\alpha$ is positive, because of the high $\mathrm{R} \& \mathrm{D}$ investment and capability in the technology leading regions (countries) compared with the late-developing regions (countries). Therefore, the R \& D effect of the technology leading regions (countries) is greater than that of the latedeveloping regions (countries).

\section{CONCLUSION}

Firstly, there is a close relationship between the technology gap, the technology spillover and technology path dependence. The path dependence of technology has a vital impact on the technology gap and the technology spillover, especially when "conscious deviation" of economic subjects happens. Action bodies make strategic and deliberate choices of technology which is closely related to the absorption efficiency of technology spillover. The strong technology dependence and "locking" will make the technology gap grow larger between the late-developing regions (countries) and the leading regions (countries), resulting in an inability to catch up with the technology.

Secondly, the technological catch-up and path dependence in late-developing regions (countries) and developed regions (countries) is related to the technological gap between the late-developing regions (countries) and developed regions (countries). When the dependence is weak, the late-developing regions (countries) can catch up with and surpass the developed regions (countries) by absorbing advanced technology and management talents, reforming the management system, breaking through the innovation technology and achieving the path innovation. At this point, technological catch-up can be achieved even there is a large technology gap between the late-developing regions (countries) and the leading regions (countries).

\section{REFERENCES}

[1] Belk R. You are What You Can Access: Sharing and Collaborative Consumption Online[J]. Journal of Business Research, 2014, 67(8): 1595-1600.

[2] SP Fraiberger, A Sundararajan. Peer-to-Peer Rental Markets in the Sharing Economy, Social Science Electronic Publishing, 2015, 68(9):1510-1555.

[3] Sundararajan, Arun. The Sharing Economy: The End of Employment and The Rise of Crowd-Based Capitalism[M]. Cambridge: The MIT Press, 2016

[4] Hamari J, Sjoklint M, Ukkonen A. The Sharing economy: Why People Participate in Collaborative Consumption[J]. Journal of the Association for Information Science and Technology, 2016, 67 (9): 2047-2059.

[5] Barro R, Sala I -Martin X. Technological Diffusion, Convergence, and Growth [J]. Journal of Economic Growth, 1997, (2): 1 -27.

[6] Basu, S. and D.N.Weil. Appropriate Technology and Growth. Quarterly Journal of Economics, 113(4):1025-1054. 1998

[7] Acemoglu, D, and F. Zilibotti. Productivty Differences. Quarterly Journal of Economics, 116(2):563-606. 2001

[8] Justin Lin, Pengfei Zhang. Appropriate Technology Technological Selection and Economic Growth in Developing countries[J]. China Economic Quarterly, 2006, 03: 985-1006.

[9] Parente, E. and E. Prescott. Barriers to technology adoption and development. Journal of Political Economy, 102(2):298-321. 1994

[10] Barro R. Sala I. Martin Economic Growth [M]. New York Mo GrawHill, 1995.

[11] Zou Wei, Dai Qian. Technological Imitation, Human Capita Accumulation and Economic Catching-up [J]. Social Sciences in China, 2003, (5): 26 -37.

[12] Ou Yangyao, Sheng Yanchao. Technology Gap, Technological Capacity and Technology Catching-up in Developing Region.[J] China Soft Science. 2008,02:153-160.

[13] Yan-chao S. Factor, Technical Ability and the Evolution of the Technical Catching-up[J]. Finance and Trade Research, 2010, 5: 010.

[14] Alberto Botta. A structuralist North-South model on structural change, economic growth and catching-up. Structural Change and Economic Dynamics, Volume 20, Issue 1, March 2009, Pages 61-73

[15] Verspagen B. A new empirical approach to catching up or falling behind $[\mathrm{J}]$. Structural change and economic dynamics, 1991, 2(2):359-380

[16] Kokko A.. Technology, Market Characteristic, and Spillovers. Journal of Development Economics, 43, 279-293. 1994

[17] Lee K.,Lim C., Technological regimes, catching-up and leapfrogging findings from Korean industries. Research Policy, 2001, (30): 459 483

[18] Lucia Cusmano, Andrea Morrison, Roberta Rabellotti. Catching up Trajectories in the Wine Sector: A Comparative Study of Chile, Italy, and South Africa. World Development, Volume 38, Issue 11, November 2010, Pages 1588-1602

[19] Xiaolan Fu, Carlo Pietrobelli, Luc Soete. The Role of Foreign Technology and Indigenous Innovation in the Emerging Economies: Technological Change and Catching-up. World Development, Volume 39, Issue 7, July 2011, Pages 1204-1212

[20] David P A. Technical choice, innovation and economic growth [M] London: Cambridge University Press, 1975.

[21] Kristensen T. Development in rich and poor countries, Praeger, New York, 1974.12

[22] Abramovitz M. A. Catching up, forging ahead and falling behind, Journal of Economic History, 1986, 46, 385-406.

[23] Baumol W. J., Batey Blackman S. A., Wolff E. N. Productivity and American Leadership: the long view, MIT Press, Cambridge, MA 1989

[24] Pasinetti, L. L. Structural Change and Economic Growth. A Theoretical Essay on the Dynamics of the Wealth of Nations, Cambridge University Press, Cambridge. 1981 